\title{
183 SKIN-DEEP; CLUES TO THE CAUSE OF PROXIMAL
} MYOPATHY

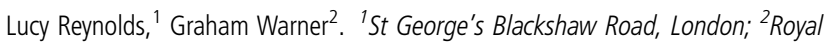
Surrey County Hospital, Guildford

10.1136/jnnp-2014-309236.183

A 50 year old gentleman re-presented to a neurology clinic with a 16 year history of upper limb girdle proximal weakness, progressively weak in his proximal lower limbs and with decline in exercise tolerance. He had been lost to follow-up following extensive tertiary-referral neurological investigation and three uninformative muscle biopsies ten years earlier. The presence of skin changes such as recent onset of extensive keloid scarring and cigarette paper scars on the skin prompted consideration of diagnosis of a collagen VI myopathy. Despite a lack of pathognomonic muscle changes on MRI, an autosomal dominant Bethlem Myopathy mutation was found in this gentleman with possible implications for his daughter of childbearing age. 